\title{
PENGARUH RETAIL MIX TERHADAP KEPUASAN PELANGGAN PADA FOODMART PRIMO LIPPO MALL KUTA
}

\author{
Adam Hermawan ${ }^{1}$ \\ Kastawan Mandala ${ }^{2}$ \\ ${ }^{1,2}$ Fakultas Ekonomi dan Bisnis Universitas Udayana, Bali, Indonesia \\ Email: adamhermawan3@gmail.com
}

\begin{abstract}
ABSTRAK
Strategi yang dapat digunakan pengusaha bisnis ritel dalam memenangkan persaingan adalah dengan menerapkan strategi retail mix yang tepat. Unsur dari bauran ritel dapat dipadukan dan dikombinasikan sedemikian rupa sehingga dapat memuaskan dan mempertahankan pelanggan yang ada. Tujuan penelitian ini adalah untuk menjelaskan pengaruh retail mix secara simultan dan secara parsial terhadap kepuasan pelanggan pada Foodmart Primo Lippo Mall Kuta. Subjek penelitian adalah adalah seluruh pelanggan Foodmart Primo Lippo Mall Kuta, dengan sampel sebanyak 115 orang. Penentuan sampel menggunakan purposive sampling method, yaitu teknik penentuan sampel dengan pertimbangan tertentu. Data di analisis menggunakan teknik analisis regresi linier berganda. Hasil penelitian menunjukkan bahwa retail mix (harga, merchandise, promosi, pelayanan, lokasi toko, dan atmosfer gerai) secara simultan dan parsial berpengaruh signifikan terhadap kepuasan pelanggan pada Foodmart Primo Lippo Mall Kuta. Hal ini memiliki makna bahwa semakin baik penerapan retail mix pada Foodmart Primo Lippo Mall Kuta maka semakin bertambah pula tingkat kepuasan pelanggan.
\end{abstract}

Kata kunci : retail mix, kepuasan pelanggan, foodmart primo lippo mall kuta

\begin{abstract}
A strategy that retail businesspeople can use to win the competition is by applying the right retail mix strategy. Elements of the retail mix can be combined and combined in such a way as to satisfy and retain existing customers. The purpose of this research is to explain the influence of retail mix simultaneously and partially to customer satisfaction at Foodmart Primo Lippo Mall Kuta. The research subjects were all Foodmart Primo Lippo Mall customers in Kuta, with a sample of 115 people. Determination of sample using purposive sampling method, that is sample determination technique with certain consideration. Data were analyzed using multiple linear regression analysis technique. The results showed that the retail mix (price, merchandise, promotion, service, store location, and store atmosphere) simultaneously and partially significant effect on customer satisfaction at Foodmart Primo Lippo Mall Kuta. This has the meaning that the better the application of the retail mix at Foodmart Primo Lippo Mall Kuta then the increase also the level of customer satisfaction.
\end{abstract}

Keyword : Retail Mix, Customer Satisfaction, Foodmart Primo Lippo Mall Kuta 


\section{PENDAHULUAN}

Perkembangan bisnis ritel di Indonesia dalam beberapa tahun terakhir dinilai cukup pesat. Menurut Asosiasi Perusahaan Ritel Indonesia (Aprindo), pertumbuhan bisnis ritel di Indonesia antara 10 persen sampai 15 persen per tahun. Dalam periode delapan tahun dari tahun 2006 hingga 2014, jumlah gerai ritel di Indonesia pada tahun 2006 sebanyak 7.713, selanjutnya tahun 2007 masih sebanyak 10.365 gerai, tahun 2008 terdapat 10.607 gerai, kemudian melompat pada tahun 2014 mencapai 26.000 gerai tersebar di hampir seluruh kota besar di Indonesia. Hal ini menunjukkan bisnis ritel di Indonesia dinilai cukup menjanjikan. Pesatnya perkembangan bisnis ritel khususnya ritel moderen ini disebabkan karena berubahnya pola berbelanja masyarakat kita yang sangat memilih melakukan pembelanjaan pada modern retail daripada di traditional market. Meningkatnya perkembangan retail modern ini mendorong persaingan dunia bisnis yang sangat ketat. Pengusaha bisnis ritel sangat perlu menerapkan sebuah strategi yang tepat agar dapat menghasilkan profit yang maksimal, memenangkan persaingan, dan dapat menciptakan kepuasan pelanggan. Strategi yang dapat digunakan pengusaha bisnis ritel dalam memenangkan persaingan adalah dengan menerapkan strategi retail mix yang tepat.

Foodmart Primo Lippo Mall Kuta merupakan perusahaan bisnis ritel yang saat ini berada diantara ketatnya persaingan bisnis ritel di Bali. Menghadapi persaingan industri ritel yang ketat di Bali, Foodmart Primo Lippo Mall Kuta telah melakukan berbagai macam strategi guna menciptakan kepuasan pelanggan sehingga dapat mempertahankan dan menarik pelanggan baru. Strategi tersebut 
antara lain dengan menetapkan strategi promosi seperti penyediaan katalog untuk menginformasikan produk baru, kemampuan ketanggapan karyawan dalam menangani keluhan guna menyalurkan layanan pelanggan terbaik kepada pelanggan. Memberikan jaminan lengkap dan keragaman barang dagangan yang disediakan pada toko, memberikan suasana toko yang nyaman contohnya dengan menyediakan tata cahaya yang terang dan alunan musik yang tenang sehingga membuat pelanggan nyaman saat berbelanja. Foodmart Primo Lippo Mall Kuta juga menyediakan potongan harga untuk beberapa item tertentu.

Perkembangan jumlah kunjungan pelanggan Foodmart Primo Lippo Mall Kuta dari bulan juli 2016 sampai bulan juli 2017 berfluktuasi. Terjadi kenaikan jumlah pengunjung di Foodmart Primo Lippo Mall Kuta pada bulan September 2016 sebanyak 3,72 persen, dibulan Desember 2016 sebesar 13,97 persen, pada bulan Januari 2017 sebanyak 2,44 persen, dibulan maret 2017 sebesar 12,5 persen, dibulan April sebanyak 1,36 persen, pada bulan Juni 2017 sebesar 3,9 persen, dan dibulan Juli 2017 mengalami peningkatan jumlah kunjungan sebanyak 5,05 persen. Namun penurunan jumlah pengunjung juga terjadi di Foodmart Primo Lippo Mall Kuta pada bulan Agustus 2016 sebesar 8,9 persen, dibulan Oktober 2016 sebanyak 3,6 persen, dibulan November 2016 sebesar 18,75 persen, dibulan Februari 2017 sebanyak 13,49 persen, dan di bulan mei 2017 mengalami penurunan pengunjung sebear 7,74 persen. Penurunan jumlah pengunjung di Foodmart Primo Lippo Mall Kuta diduga dapat terjadi karena masih belum maksimalnya kepuasan pelanggan yang dapat dilihat dari masih terdapat keluhan pelanggan pada Foodmart Primo Lippo Mall Kuta. Belum tercapainya kepuasan 
pelanggan yang maksimal, masih terdapat keluhan dari segi harga, Variasi merek produk, dan promosi yang merupakan bagian dari Retail Mix. Oleh sebab itu penulis tertarik untuk meneliti pengaruh retail mix terhadap kepuasan pada Foodmart Primo Lippo Mall Kuta.

Penelitian sebelumnya yang dilakukan Maheza dan Kusumadewi (2015) dalam penelitian yang berjudul "Pengaruh Retail Mix terhadap Kepuasan Pelanggan pada Unagi Bali Handycraft and Souvenir Gallery di Kota Denpasar” menyimpulkan bahwa 1) bauran ritel (price, barang dagangan, service, store location, promotion, dan suasana gerai ritel) secara simultan memberikan pengaruh kepada customer satisfaction di Unagi Bali Handycraft and Souvenir Gallery di Kota Denpasar. 2) bauran ritel (price, barang dagangan, service, store location, promotion, dan suasana gerai ritel) secara parsial memberikan pengaruh yang positif dan signifikan kepada customer satisfaction pada Unagi Bali Handycraft and Souvenir Gallery di Kota Denpasar. 3) Variabel bauran ritel yang sangat berperan memberikan pengaruh kepada customer satisfaction adalah variabel suasana gerai toko di Unagi Bali Handycraft and Souvenir Gallery di Kota Denpasar.

Kata ritel berasal dari bahasa Perancis, ritellier, yang berarti memotong atau memecah sesuatu menjadi bagian yang lebih kecil. Jadi bisa dikatakan ritel adalah suatu penjualan dari sejumlah kecil komoditas kepada konsumen. Ritel adalah seluruh aktivitas perdagangan barang atau jasa dengan cara langsung ke pelanggan tingkat akhir sebagai konsumsi pribadi maupun keperluan keluarga, tidak dalam bentuk kebuthan usaha. Retailing bisa dijelaskan sebagai seluruh 
aktivitas yang berkaitan kepada kegiatan distribusi dan penjualan produk dengan cara langsung ke pelanggan, yang mana secara fokus dari kegiatan itu ditujukan agar mempertinggi nilai produk yang digunakan untuk pribadi dan tidak untuk usaha (Utami, 2010). Marketing mix adalah hal yang mendasar pada strategi pemasaran yang dilaksanakan usaha ritel. Diterapkannya marketing mix dipastikan dapat menjadi daya tarik tersendiri untuk para pelanggan dalam pemilihan suatu usaha ritel agar dapat melaksanakan transaksi beli untuk suatu produk pada masalah pemenuhan keperluan dan juga kebutuhannya. Berdasarkan Utami (2010) retail marketing mix merupakan strategi marketing yang menggunakan beberapa variable sebagai acuannya, yang mana para pemilik ritel bisa membuat kombinasi dari sejumlah variable itu dan membentuk jalan lain untuk usaha menarik konsumen.

Bauran pemasaran ritel terdiri dari enam elemen yang meliputi: 1) Lokasi: merupakan faktor yang sangat penting dalam bauran pemasaran ritel. Pada lokasi yang tepat, sebuah gerai akan lebih sukses dibandingkan gerai lainnya yang berlokasi kurang strategis, meskipun keduanya menjual produk yang sama, oleh wiraniaga yang sama banyaknya, dan sama terampilnya, dan sama-sama punya pengaturan atmosfer yang bagus. 2) Merchandise: merupakan keseluruhan produk yang dijual oleh peritel dalam gerai. 3) Harga: penetapan harga dalam pemasaran ritel merupakan hal yang penting mengingat penetapan harga akan menghasilkan dampak yang besar bagi usaha ritel itu sendiri karena akan menentukan laba/rugi yang akan diperoleh peritel. 4) Promosi: promosi merupakan salah satu faktor penentu keberhasilan suatu program pemasaran usaha ritel. Kegiatan promosi 
yang dilakukan oleh peritel biasanya bertujuan untuk menginformasikan, mempengaruhi, dan membujuk serta mengingatkan pelanggan sasaran tentang perusahaan dan bauran pemasarannya. Program promosi yang biasanya diterapkan oleh peritel terdiri atas iklan, sales promotion, public relations (publisitas), dan personal selling. 5) Atmosfer gerai: atmosfer atau suasana gerai berperan penting dalam memikat pembeli dan membuat nyaman pembeli dalam memilih barang belanjaan. Atmosfer yang dimaksud adalah suasana dan ambience yang tercipta dari gabungan unsur-unsur desain gerai, perencanaan gerai, komunikasi visual, dan penyajian merchandise (display barang). 6) Pelayanan ritel: bertujuan untuk memberikan berbagai jenis fasilitas kepada konsumen saat konsumen melakukan kegiatan belanja dalam gerai ritel. Pelayanan ritel bersama unsur-unsur bauran pemasaran ritel lainnya mempunyai fungsi memenuhi kebutuhan pembeli dalam berbelanja.

Merchandise merupakan produk-produk yang dijual peritel dalam gerainya. Sedangkan Merchandising adalah kegiatan pengadaan barang-barang yang sesuai dengan bisnis yang dijalani toko untuk disediakan dengan jumlah, waktu, dan harga yang sesuai untuk mencapai sasaran toko atau perusahaan ritel. Merchandising merupakan salah satu bidang yang berperan menentukan keunggulan bersaing dari peritel. Konsumen akan memberikan kesan yang baik terhadap suatu toko apabila toko tersebut dapat menyediakan barang yang dibutuhkan dan dinginkan oleh konsumen (Utami, 2010:86). Utami (2010:86) menyatakan faktor-faktor yang dijadikan suatu pertimbangan bagi sebuah usaha ketika menentukan barang dan jasa yang akan dijualnya, yaitu: 1) variety, lengkap 
atau tidaknya barang dan jasa yang akan diperdagangkan bisa memengaruhi keputusan pembeli pada saat menentukan toko atau department store mana yang akan dikunjungi. 2) Width or breath, adanya barang atau jasa pendamping dari produk utama yang disediakan. 3) kedalaman, jenis dan macam kegunaan dari sebuah barang atau jasa. 4) konsistensi, barang yang telah cocok untuk memenuhi kebutuhan pembeli haruslah selalu dikontrol ketersediaannya melalui cara menjaga kelengkapannya, kualitasnya, dan harganya dari barang yang akan diperjualbelikan. 5) Balance, berhubungan dengan sebuah kegiatan untuk menentukan penyesuaian jenis dan macam barang yang akan diperjualbelikan sesuai pasar ditargetkan.

Menurut Levy dan Weitz (2009:375) retail pricing adalah nilai yang dirasakan oleh pelanggan dan rasio yang diterima oleh pelanggan. Dari sudut pandang konsumen, Harga sering kali digunakan sebagai indikator nilai bagaimana Harga tersebut dihubungkan dengan manfaat yang dirasakan atas suatu barang dan jasa. Bagi pelaku usaha, penetapan harga pada suatu produk bertujuan untuk melakukan product positioning di arena pasar (Nitisusastro, 2012:200). Penetapan Harga merupakan faktor yang paling sulit di antara unsur-unsur dalam bauran pemasaran ritel lainnya dan Harga juga merupakan satu-satunya unsur yang bakal mendatangkan laba bagi peritel. Menurut Utami (2010:87) dalam menetapkan harga, terdapat tiga macam strategi Harga yang pada umumnya digunakan sebagai dasar oleh para peritel yaitu: 1) Penetapan Harga di bawah Harga pasar, 2) Penetapan Harga sesuai dengan Harga pasar dan 3) Penetapan Harga diatas Harga pasar. 
Menurut Utami (2010:88) promosi merupakan kegiatan yang mempengaruhi persepsi, sikap, dan perilaku konsumen terhadap suatu toko ritel dengan segala penawarannya. Utami (2010:88) membagi tiga macam alat promosi yang sering digunakan oleh peritel, yaitu: 1) Iklan, segala bentuk presentasi nonpersonal dan promosi dari barang-barang serta pelayanan oleh sebuah sponsor tertentu yang dapat dolakukan melalui berbagai media seperti televise, radio, majalah, surat kabar, katalog, dan media lainnya, 2) Penjualan langsung, bentuk persentasi lisan dalam suatu percakapan dengan satu atau beberapa orang calon pembeli dengan tujuan untuk mencapai kesepakatan pembelian. Cara ini biasanya dilakukan dengan menggunakan tenaga wiraniaga. 3) Promosi penjualan, merupakan aktivitas yang dapat merangsang konsumen untuk membeli yang meliputi pemajangan, pameran, pertunjukkan, dan demontrasi. Bentuk promosi penjualan, antara lain dengan pemberian sampel dan kupon hadiah.

Menurut Utami (2010:88) pelayanan merupakan suatu keinginan konsumen untuk dilayani, dan pelayanan tersebut tentunya berhubungan dengan penjualan produk yang akan dibeli konsumen. Utami (2010:88) juga mendefinisikan pelayanan sebagai aktivitas, manfaat, kepuasan dari sesuatu yang ditawarkan dalam penjualan. Para pengusaha ritel harus dapat menyesuaikan jenis layanan yang ditawarkan dengan unsur-unsur lainnya dalam bauran ritel. Berbagai jenis pelayanan yang ditawarkan dapat membedakan pelayanan antara toko yang satu dengan toko yang lainnya, sehingga dapat disimpulkan bahwa semakin lengkap dan memuaskan pelayanan yang diberikan oleh suatu toko, maka semakin besar 
kemungkinan konsumen akan tertarik untuk memilih berbelanja di suatu toko yang bersangkutan (Utami, 2010:88).

Desain toko yang baik akan menarik banyak konsumen untuk datang. Penampilan serta performa dari toko eceran memposisikan image toko dalam benak konsumen. Menurut Levy dan Weitz (2001:576) atmosfer adalah mendesain suatu lingkungan melalui komunikasi visual, pencahayaan, warna, musik, dan penciuman untuk merangsang persepsi dan emosi dari pelanggan dan pada akhirnya untuk mempengaruhi perilaku pembelanjaan mereka. Mencari dan menentukan lokasi merupakan tugas penting bagi peritel, karena penentuan lokasi yang tepat merupakan kunci kesuksesan suatu bisnis (Utami, 2010:89). Pada lokasi yang tepat, sebuah gerai akan lebih sukses dibandingkan gerai lainnya yang berlokasi kurang strategis, meskipun keduanya menjual produk yang sama, oleh pramuniaga yang sama banyak dan terampil, dan sama-sama punya setting ambience yang bagus.

Penelitian yang membahas tentang pengaruh retail mix terhadap kepuasan pelanggan telah banyak dilakukan, seperti penelitian yang dilakukan Artha (2013) dalam penelitian yang berjudul "Analisis Pengaruh Retailing Mix terhadap Kepuasan Pelanggan dan Dampaknya terhadap Loyalitas Pelanggan pada Giant Supermarket Kota Malang" menyimpulkan bahwa variabel retailing mix (produk, Harga, iklan dan promosi, lokasi pelayanan, serta desain dan tampilan toko) berpengaruh positif dan signifikan secara simultan dan parsial terhadap kepuasan pelanggan dan loyalitas pelanggan. Dalam penelitian yang dilakukan oleh Arokiasamy (2012) yang berjudul "The Effect of Marketing Mix and Customer 
Perception on Brand Loyalty" menemukan yaitu strategi bauran ritel tersebut terdiri atas barang dagangan, harga, communication, desain toko, pelayanan pelanggan dan lokasi dengan terus menerus memberikan pengaruh signifikan kepada customer satisfaction. Berdasarkan paparan yang telah diuraikan sebelumnya maka dapat dirumuskan hipotesis penelitian sebagai berikut.

$\mathrm{H}_{1}$ : Retail mix secara simultan berpengaruh positif terhadap Kepuasan pelanggan pada pada Foodmart Primo Lippo Mall Kuta

Hasil penelitian Khan et al. (2012) yang berjudul Determinants of Customer Satisfaction in Fast Food Industry memberikan hasil bahwa terdapat pengaruh positif antara promosi terhadap kepuasan pelanggan. Sehingga semakin tinggi promosi diharapkan memberikan dampak positif pada kepuasan pelanggan. Kesimpulan penelitian Melissa (2010) yang berjudul "Pengaruh Retail Service dan Store Image terhadap Kepuasan dan Loyalitas Pelanggan di Pepito Supermarket Kuta-Bali" menjelaskan bahwa layanan ritel berpengaruh langsung secara positif dan signifikan terhadap kepuasan pelanggan Pepito Supermarket. Fang (2012) dalam penelitiannya yang berjudul pengaruh "faktor faktor retailing mix terhadap kepuasan konsumen berbelanja di swakayan surya baru pati" menyimpulkan bahwa pelayanan memiliki pengaruh signifikan terhadap kepuasan konsumen.

Faktor yang paling dominan adalah pelayanan. Hasil penelitian Tim dan Dion (2017) yang berjudul "pengaruh Atmosfer Gerai, Promosi Penjualan dan Pelayanan Ritel terhadap Kepuasan Pelanggan dan Dampaknya terhadap Loyalitas Pelanggan Ritel di Lotte Mart Kelapa Gading” menyimpulkan bahwa Variabel atmosfer gerai berpengaruh terhadap kepuasan pelanggan Lotte Mart Kelapa 
Gading. Semakin baik (memberikan kenyamanan dan kemudahan) atmosfer gerai maka akan semakin tinggi kepuasan pelanggan. Berdasarkan hasil penelitian yang telah diuraikan sebelumnya maka dapat dirumuskan hipotesis penelitian sebagai berikut.

$\mathrm{H}_{2}$ : Retail mix secara parsial berpengaruh positif terhadap Kepuasan pelanggan pada Foodmart Primo Lippo Mall Kuta.

\section{METODE PENELITIAN}

Pendekatan yang digunakan pada penelitian ini adalah pendekatan kuantitatif yang berbentuk asosiatif. Penelitian ini membahas pengaruh retail mix yang meliputi merchandise, Harga, promosi, pelayanan, lokasi gerai, dan atmosfer gerai terhadap kepuasan pelanggan. Berdasarkan kajian pustaka dan rumusan hipotesis yang telah dipaparkan maka model konseptual penelitian dapat digambarkan sebagai berikut:

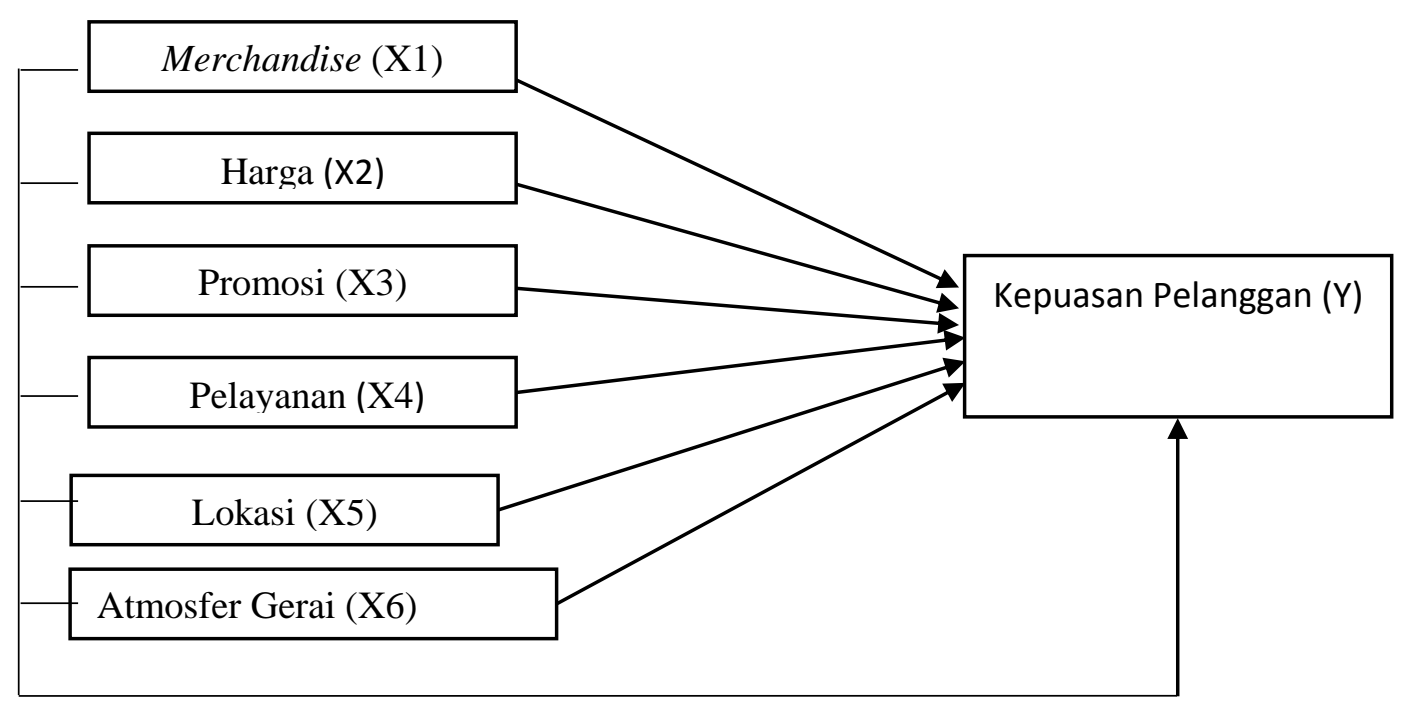

\section{Gambar 1. Desain Penelitian}

Sumber: Data Diolah, 2017 
Penelitian ini dilakukan di Foodmart Primo Lippo Mall Kuta. Lokasi ini dipilih karena sampai saat ini belum teridentifikasi terdapatnya penelitian di Foodmart Primo Lippo Mall Kuta tentang pengaruh retail mix terhadap kepuasan pelanggan. Lokasi ini juga dipilih karena masih terdapat keluhan pelanggan dibidang Retail mix. Subjek dalam penelitian ini adalah seluruh pelanggan Foodmart Primo Lippo Mall Kuta. Objek penelitian ini adalah mengenai pengaruh retail mix terhadap kepuasan pelanggan pada Foodmart Primo Lippo Mall Kuta.

Variabel-variabel yang diteliti dalam penelitian ini yaitu sebagai berikut: Variabel dependen atau yang sering disebut variabel terikat adalah variabel yang terkena pengaruh ataupun variabel akibat, dikarenakan dengan munculnya variabel independen atau bebas (Sugiyono, 2014:59). Variabel dependen (Y) pada penelitian ini yaitu kepuasan pelanggan. Variabel independen sering disebut variabel bebas adalah variabel yang memberikan pengaruh atau yang disebut sebab dari perubahan atau munculnyanya variabel dependen atau terikat (Sugiyono, 2014:59). Variabel independen (X) pada karya ilmiah ini yaitu merchandise (X1), Harga (X2), promosi (X3), pelayanan (X4), lokasi gerai (X5), atmosfer gerai (X6).

Merchandise (X1) diukur dengan menggunakan indikator yang dikutip dari Nurbiyanto, dkk (2010) dan Supiatni (2012), yaitu, sejauh mana produk yang ditawarkan Foodmart Primo Lippo Mall Kuta memuaskan kebutuhan konsumen, kelengkapan untuk setiap jenis produk dan Foodmart Primo Lippo Mall Kuta menawarkan beragam jenis merek produk. Harga (X2) diukur dengan menggunakan indikator yang dikutip dari Nurbiyanto, dkk (2010), yakni sebagai 
berikut, harga yang ditawarkan Foodmart Primo Lippo Mall Kuta sesuai dengan kualitas produknya, Foodmart Primo Lippo Mall Kuta memiliki Harga yang lebih murah dibandingkan toko lainnya dan pemotongan harga dari harga normal yang dilakukan Foodmart Primo Lippo Mall Kuta untuk menarik pelanggan untuk terus berbelanja di Foodmart Primo Lippo Mall Kuta.

Promosi (X3) diukur dengan menggunakan indikator yang dikutip dari Hendro, dkk (2013) dan Nanang (2013) adalah, Foodmart Primo Lippo Mall Kuta menyediakan katalog untuk mengiklankan produk baru dan produk yang akan didiskonkan agar memberikan ketertarikan kepada konsumen untuk membelinya, penyediaan hadiah, Foodmart Primo Lippo Mall Kuta menyediakan hadiah untuk pembelian produk tertentu dan mengajak konsumen untuk mengumpulkan nama mereka untuk diundi. Pelayanan (X4) diukur dengan menggunakan indikator yang dikutip dari Anggraeni (2014), Grewal (2009), dan Borges (2012), yakni sebagai berikut, waktu jam buka sampai dengan jam tutup yang disediakan Foodmart Primo Lippo Mall Kuta, karyawan di Foodmart Primo Lippo Mall Kuta menangani keluhan konsumen dengan cepat dan keramahan karyawan di Foodmart Primo Lippo Mall Kuta dalam melayani konsumen.

Lokasi (X5) diukur dengan menggunakan indikator yang dikutip dari Supiatni (2012) dan Autami (2015), yakni sebagai berikut: letak dari Foodmart Primo Lippo Mall Kuta mudah dijangkau dan terletak di kawasan pusat kota, jalan disekitar Foodmart Primo Lippo Mall Kuta mudah dilalui dan penyediaan lahan parkir yang luas. Atmosfer gerai (X6) diukur dengan menggunakan indikator yang dikutip dari Hendro dkk. (2013) dan Sandra (2013), yakni sebagai berikut: 
pencahayaan ruangan gerai Foodmart Primo Lippo Mall Kuta yang cukup terang sehingga dapat menciptakan kenyamanan bagi pelanggan, alunan music yang diputar dengan tempo yang normal dalam gerai Foodmart Primo Lippo Mall Kuta dan aroma yang menyegarkan dalam gerai Foodmart Primo Lippo Mall Kuta.

Kepuasan pelanggan (Y) diukur dengan menggunakan indikator yang dikutip dari Kotler dan Armstrong (2008:16) dan Maheza dan Kusumadewi (2015), yakni sebagai berikut kepuasan yang dirasakan oleh pelanggan di Foodmart Primo Lippo Mall Kuta, pelanggan merasakan senang berbelanja di Foodmart Primo Lippo Mall Kuta, pelanggan ingin melakukan pembelian ulang di Foodmart Primo Lippo Mall Kuta dan pelanggan akan merekomendasikan berbelanja di Foodmart Primo Lippo Mall Kuta kepada orang-orang atau kerabat terdekatnya.

Jenis data yang digunakan dalam penelitian ini berdasarkan sifatnya, yaitu data kuantitatif dalam penelitian ini dalam bentuk tabulasi data yang dilaksanakan berdasar dari jawaban atas kuesioner yang telah dibagikan. Pada pengujian berikut data kualitatif berwujud sejarah dibentuknya perusahaan, visi misi, data keluhanan pelanggan, dan juga jawaban yang telah diutarakan responden pada kuesioner yang diberikan. Dalam penelitian ini data primer yang digunakan adalah data dari hasil penyebaran kuesioner. Sumber sekunder pada penelitian ini adalah data-data olahan yang diperoleh dari berbagai sumber, seperti laporan data keluhan pelanggan dan sejarah perusahaan.

Populasi dalam penelitian ini adalah pelanggan Foodmart Primo Lippo Mall Kuta. Sampel merupakan bagian dari jumlah dan karakteristik yang dimiliki 
populasi tersebut (Sugiyono, 2014:116). Sampel yang digunakan dalam penelitian ini adalah pelanggan Foodmart Primo Lippo Mall Kuta. Penelitian ini menggunakan 23 indikator sehingga banyaknya responden yang diambil sebagai sampel adalah $5 \times 23=115$ responden. Teknik pengambilan sampel yang digunakan dalam penelitian ini adalah purposive sampling method. Menurut Sugiyono(2014:122) purposive sampling adalah teknik penentuan sampel dengan pertimbangan tertentu. Kriteria yang digunakan untuk menentukan anggota sampel dalam penelitian pada Foodmart Primo Lippo Mall Kuta adalah pelanggan yang telah berbelanja di Foodmart Primo Lippo Mall Kuta lebih dari sekali dan memiliki umur diatas 17 tahun dengan alasan mempunyai kemampuan untuk memahami dan mengisi kuesioner.

Metode pengumpulan data yang digunakan dalam penelitian ini adalah dengan menggunakan kuesioner. Pada penelitian ini, kuesioner diberikan kepada konsumen Foodmart Primo Lippo Mall Kuta mengenai retail mix dan kepuasan pelanggan. Skala pengukuran yang digunakan adalah skala Likert untuk mengukur pendapat dan persepsi seseorang tentang fenomena social. Data yang dikumpulkan dalam penelitian ini akan dianalisis dengan cara regresi linear berganda. Analisis ini dipakai untuk mengetahui ketergantungan suatu variabel terikat dengan satu atau lebih variabel bebas. Penelitian ini menggunakan model regresi linear berganda yang dibantu dengan program statistical package for social science (SPSS) untuk menganalisis pengaruh retail mix terhadap kepuasan pelanggan pada Foodmart Primo Lippo Mall Kuta. Adapun bentuk umum dari 
persamaan regresi linear berganda menurut suntoyo (2011:61) adalah sebagai berikut:

$$
\mathrm{Y}=\alpha+\beta_{1} X_{1}+\beta_{2} X_{2}+\beta_{3} X_{3}+\beta_{4} X_{4}+\beta_{5} X_{5}+\beta_{6} X_{6}+\ell_{i}
$$

\section{Keterangan}

$\mathrm{Y}=$ Kepuasan pelanggan

$\alpha=$ Konstanta

$X_{1}=$ Merchindise/produk

$X_{2}=$ Price $/$ Harga

$X_{3}=$ Promotion/promosi

$X_{4}=$ Retail service/pelayanan

$X_{5}=$ Place/lokasi

$X_{6}=$ Atsmosfer gerai/suasana

$\beta_{1}=$ Koefisien Regresi variabel merchandise

$\beta_{1}=$ Koefisien Regresi variabel Harga

$\beta_{1}=$ Koefisien Regresi variabel promosi

$\beta_{1}=$ Koefisien Regresi variabel pelayanan

$\beta_{1}=$ Koefisien Regresi variabel lokasi toko

$\beta_{1}=$ Koefisien Regresi variabel atmosfer gerai

$\mathrm{E}=$ error

\section{HASIL DAN PEMBAHASAN}

Hasil uji validitas menunjukkan bahwa seluruh variabel memiliki nilai koefisien korelasi dengan skor total seluruh item pernyataan lebih besar dari 0,30 . Hal ini menunjukkan bahwa butir-butir pernyataan dalam instrumen penelitian tersebut valid dan dapat dilanjutkan ke analisa berikutnya. Hasil uji reliabilitas menunjukkan bahwa seluruh instrumen penelitian memiliki koefisien Cronbach's Alpha lebih dari 0,60 menunjukan bahwa pengukuran tersebut dapat memberikan hasil yang konsisten apabila dilakukan pengukuran kembali terhadap subyek yang sama pada waktu yang berbeda. Penilaian responden mengenai aspek Merchandise pada Foodmart Primo Lippo Mall Kuta diukur dengan 3 item pernyataan yang disajikan pada Tabel 1 tersebut. 
Tabel 1

Proporsi Jawaban Responden Mengenai Variabel Merchandise

\begin{tabular}{|c|c|c|c|c|c|c|c|}
\hline \multirow{2}{*}{ Pernyataan } & \multicolumn{5}{|c|}{ Proporsi Jawaban Responden (\%) } & \multirow{2}{*}{ Rata-rata } & \multirow{2}{*}{ Kriteria } \\
\hline & STS & TS & $\mathbf{N}$ & $\mathbf{S}$ & SS & & \\
\hline $\begin{array}{l}\text { Foodmart Primo Lippo Mall } \\
\text { Kuta menawarkan produk } \\
\text { yang berkualitas. }\end{array}$ & 0 & 1,7 & 11,3 & 56,5 & 30,4 & 04.16 & Baik \\
\hline $\begin{array}{l}\text { Foodmart Primo Lippo Mall } \\
\text { Kuta memiliki kelengkapan } \\
\text { untuk setiap jenis produk } \\
\text { yang ditawarkan. }\end{array}$ & 0,9 & 1,7 & 14,8 & 52,2 & 30,4 & 04.10 & Baik \\
\hline $\begin{array}{l}\text { Foodmart Primo Lippo Mall } \\
\text { Kuta menawarkan berbagai } \\
\text { jenis merek produk. }\end{array}$ & 0,9 & 0,9 & 12,2 & 52,2 & 33,9 & 04.17 & Baik \\
\hline & ata-rat & & & & & 4,14 & Baik \\
\hline
\end{tabular}

Berdasarkan data tersebut dapat ditentukan skor rata-rata variabel

Merchandise adalah sebesar 4,14 yang berada pada rentang kriteria 3,41 - 4,20

yang berarti baik, dengan demikian secara umum responden menilai bahwa aspek

merchandise yang tersedia di Foodmart Primo Lippo Mall Kuta sudah baik.

Tabel 2

Proporsi Jawaban Responden Mengenai Variabel Harga

\begin{tabular}{|c|c|c|c|c|c|c|c|}
\hline \multirow{2}{*}{ Pernyataan } & \multicolumn{5}{|c|}{ Proporsi Jawaban Responden (\%) } & \multirow{2}{*}{ Rata-rata } & \multirow{2}{*}{ Kriteria } \\
\hline & STS & TS & $\mathbf{N}$ & $\mathbf{S}$ & SS & & \\
\hline $\begin{array}{l}\text { Harga yang ditawarkan } \\
\text { Foodmart Primo Lippo Mall } \\
\text { Kuta sesuai dengan kualitas } \\
\text { produk }\end{array}$ & 0 & 1,7 & 21,7 & 46,1 & 30,4 & 4,05 & Baik \\
\hline $\begin{array}{l}\text { Foodmart Primo Lippo Mall } \\
\text { Kuta menawarkan harga yang } \\
\text { lebih murah dibandingkan retail } \\
\text { lainnya }\end{array}$ & 0,9 & 3,5 & 26,1 & 40,9 & 28,7 & 3,93 & Baik \\
\hline $\begin{array}{l}\text { Foodmart Primo Lippo Mall } \\
\text { Kuta memberikan potongan } \\
\text { harga/diskon terhadap produk- } \\
\text { produk tertentu }\end{array}$ & 0 & 2,6 & 26,1 & 42,6 & 28,7 & 3,97 & Baik \\
\hline \multicolumn{6}{|c|}{ Rata-rata } & 3,98 & Baik \\
\hline
\end{tabular}

Sumber: Data Diolah, 2017

Penilaian responden mengenai aspek harga pada Foodmart Primo Lippo

Mall Kuta diukur dengan 3 item pernyataan yang disajikan pada Tabel 2 berikut.

Berdasarkan data tersebut dapat ditentukan skor rata-rata variabel harga adalah

sebesar 3,98 yang berada pada rentang kriteria 3,41 - 4,20 yang berarti baik, 
dengan demikian secara umum responden menilai bahwa aspek harga yang ditawarkan di Foodmart Primo Lippo Mall Kuta sudah baik sesuai dengan kualitas produk yang diberikan.

Penilaian responden mengenai aspek promosi pada Foodmart Primo Lippo Mall Kuta diukur dengan 3 item pernyataan yang disajikan pada Tabel 3 berikut.

\section{Tabel 3}

Proporsi Jawaban Responden Mengenai Variabel Promosi

\begin{tabular}{|c|c|c|c|c|c|c|c|}
\hline \multirow{2}{*}{ Pernyataan } & \multicolumn{5}{|c|}{ Proporsi Jawaban Responden (\%) } & \multirow{2}{*}{ Rata-rata } & \multirow{2}{*}{ Kriteria } \\
\hline & STS & TS & $\mathbf{N}$ & $\mathbf{S}$ & SS & & \\
\hline $\begin{array}{l}\text { Foodmart Primo Lippo Mall } \\
\text { Kuta menyediakan katalog } \\
\text { untuk menginformasikan } \\
\text { produk baru dan berbagai } \\
\text { diskon yang ditawarkan }\end{array}$ & 0 & 1,7 & 14,8 & 52,2 & 31,3 & 4,13 & Baik \\
\hline $\begin{array}{l}\text { Foodmart Primo Lippo Mall } \\
\text { Kuta menyediakan hadiah untuk } \\
\text { pembelian produk tertentu }\end{array}$ & 0 & 2,6 & 22,6 & 48,7 & 26,1 & 3,98 & Baik \\
\hline $\begin{array}{l}\text { Foodmart Primo Lippo Mall } \\
\text { Kuta mengadakan undian } \\
\text { dengan berbagai hadiah yang } \\
\text { menarik }\end{array}$ & 0 & 1,7 & 33 & 36,5 & 28,7 & 3,92 & Baik \\
\hline \multicolumn{6}{|c|}{ Rata-rata } & 4,01 & Baik \\
\hline
\end{tabular}

Berdasarkan data tersebut dapat ditentukan skor rata-rata variabel promosi adalah sebesar 4,01 yang berada pada rentang kriteria 3,41 - 4,20 yang berarti baik, dengan demikian secara umum responden menilai bahwa aspek promosi yang dilakukan Foodmart Primo Lippo Mall Kuta sudah baik dalam menarik perhatian pelanggan. Penilaian responden mengenai aspek pelayanan yang tersedia di Foodmart Primo Lippo Mall Kuta diukur dengan 3 item pernyataan yang disajikan pada Tabel 4 berikut. Berdasarkan data tersebut dapat ditentukan skor rata-rata variabel pelayanan adalah sebesar 3,97 yang berada pada rentang kriteria 3,41 - 4,20 yang berarti baik, dengan demikian secara umum responden 
menilai bahwa aspek pelayanan yang diberikan Foodmart Primo Lippo Mall Kuta kepada pelanggan sudah baik.

\section{Tabel 4}

Proporsi Jawaban Responden Mengenai Variabel Pelayanan

\begin{tabular}{|c|c|c|c|c|c|c|c|}
\hline \multirow{2}{*}{ Pernyataan } & \multicolumn{5}{|c|}{ Proporsi Jawaban Responden (\%) } & \multirow{2}{*}{ Rata-rata } & \multirow{2}{*}{ Kriteria } \\
\hline & STS & TS & $\mathbf{N}$ & $\mathbf{S}$ & SS & & \\
\hline $\begin{array}{l}\text { Waktu buka dan tutup gerai } \\
\text { disediakan Foodmart Primo } \\
\text { Lippo Mall Kuta sudah sesuai } \\
\text { dengan yang diinformasikan }\end{array}$ & 0 & 1,7 & 27,8 & 45,2 & 25,2 & 3,94 & Baik \\
\hline $\begin{array}{l}\text { Karyawan di Foodmart Primo } \\
\text { Lippo Mall Kuta menangani } \\
\text { keluhan konsumen secara cepat }\end{array}$ & 0 & 0,9 & 27 & 48,7 & 23,5 & 3,95 & Baik \\
\hline $\begin{array}{l}\text { Karyawan Foodmart Primo Lippo } \\
\text { Mall Kuta melayani saya dengan } \\
\text { ramah dan sopan }\end{array}$ & 0 & 0,9 & 27,8 & 39,1 & 32,2 & 4,03 & Baik \\
\hline \multicolumn{6}{|c|}{ Rata-rata } & 3,97 & Baik \\
\hline
\end{tabular}

Sumber: Data Diolah, 2017

Penilaian responden mengenai aspek lokasi Foodmart Primo Lippo Mall

Kuta diukur dengan 3 item pernyataan yang disajikan pada Tabel 5 berikut.

Berdasarkan data tersebut dapat ditentukan skor rata-rata variabel lokasi adalah sebesar 4,08 yang berada pada rentang kriteria 3,41 - 4,20 yang berarti baik, dengan demikian secara umum responden menilai bahwa aspek lokasi Foodmart Primo Lippo Mall Kuta sudah baik dan mudah dijangkau oleh pelanggan.

Tabel 5

Proporsi Jawaban Responden Mengenai Variabel Lokasi

\begin{tabular}{|c|c|c|c|c|c|c|c|}
\hline \multirow{2}{*}{ Pernyataan } & \multicolumn{5}{|c|}{ Proporsi Jawaban Responden (\%) } & \multirow{2}{*}{ Rata-rata } & \multirow{2}{*}{ Kriteria } \\
\hline & STS & TS & $\mathbf{N}$ & $\mathbf{S}$ & SS & & \\
\hline Lokasi Foodmart Primo & & & & & & & \\
\hline $\begin{array}{l}\text { Lippo Mall Kuta yang mudah } \\
\text { dijangkau karena terletak di } \\
\text { kawasan pusat kota }\end{array}$ & 0 & 6,1 & 10,4 & 51,3 & 32,2 & 4,1 & Baik \\
\hline $\begin{array}{l}\text { Akses menuju Foodmart } \\
\text { Primo Lippo Mall Kuta } \\
\text { mudah dan lancar }\end{array}$ & 0,9 & 7 & 20,9 & 48,7 & 22,6 & 3,85 & Baik \\
\hline $\begin{array}{l}\text { Foodmart Primo Lippo Mall } \\
\text { Kuta menyediakan lahan } \\
\text { parkir yang luas }\end{array}$ & 0 & 0,9 & 13 & 41,7 & 44,3 & 4,3 & Sangat Baik \\
\hline \multicolumn{6}{|c|}{ Rata-rata } & 4,08 & Baik \\
\hline
\end{tabular}

Sumber: Data Diolah, 2017 
Penilaian responden mengenai aspek atmosfer gerai Foodmart Primo Lippo Mall Kuta diukur dengan 4 item pernyataan yang disajikan pada Tabel 6 berikut. Berdasarkan data tersebut dapat ditentukan skor rata-rata variabel atmosfer gerai adalah sebesar 3,96 yang berada pada rentang kriteria 3,41 - 4,20 yang berarti baik, dengan demikian secara umum responden menilai bahwa atmosfer gerai Foodmart Primo Lippo Mall Kuta sudah baik, sehingga menciptakan kenyamanan berbelanja pada pelanggan.

Tabel 6

Proporsi Jawaban Responden Mengenai Variabel Atmosfer Gerai

\begin{tabular}{|c|c|c|c|c|c|c|c|}
\hline \multirow{2}{*}{ Pernyataan } & \multicolumn{5}{|c|}{ Proporsi Jawaban Responden (\%) } & \multirow{2}{*}{ Rata-rata } & \multirow{2}{*}{ Kriteria } \\
\hline & STS & TS & $\mathbf{N}$ & $\mathbf{S}$ & SS & & \\
\hline $\begin{array}{l}\text { Pencahayaan ruangan Foodmar } \\
\text { Primo Lippo Mall Kuta terang } \\
\text { sehingga menciptakan } \\
\text { kenyamanan saat berbelanja }\end{array}$ & 0 & 0,9 & 30,4 & 37,4 & 31,3 & 3,99 & Baik \\
\hline $\begin{array}{l}\text { Foodmart Primo Lippo Mall } \\
\text { Kuta memutar alunan music } \\
\text { dengan nada yang nyaman }\end{array}$ & 0 & 2,6 & 27,8 & 38,3 & 31,3 & 3,98 & Baik \\
\hline $\begin{array}{l}\text { Aroma yang menyegarkan } \\
\text { dalam gerai Foodmart Primo } \\
\text { Lippo Mall Kuta }\end{array}$ & 0 & 1,7 & 22,6 & 50,4 & 25,2 & 3,99 & Baik \\
\hline $\begin{array}{l}\text { Foodmart Primo Lippo Mall } \\
\text { Kuta menggunakan system } \\
\text { pengaturan udara dengan } \\
\text { menggunakan AC }\end{array}$ & 0 & 1,7 & 35,7 & 33,9 & 28,7 & 3,9 & Baik \\
\hline \multicolumn{6}{|c|}{ Rata-rata } & 3,96 & Baik \\
\hline
\end{tabular}

Sumber: Data Diolah, 2017

Penilaian responden mengenai aspek kepuasan pelanggan Foodmart Primo Lippo Mall Kuta diukur dengan 4 item pernyataan yang disajikan pada Tabel 7. Berdasarkan data tersebut dapat ditentukan skor rata-rata variabel kepuasan pelanggan adalah sebesar 4,13 yang berada pada rentang kriteria 3,41 - 4,20 yang berarti baik, dengan demikian secara umum responden memperoleh kepuasan setelah berbelanja di Foodmart Primo Lippo Mall Kuta. Nilai Kolmogorov 
Sminarnov (K-S) sebesar 0,648, sedangkan nilai Asymp. Sig. (2-tailed) sebesar 0,796 .

\section{Tabel 7}

Proporsi Jawaban Responden Mengenai Variabel Kepuasan Pelanggan

\begin{tabular}{|c|c|c|c|c|c|c|c|}
\hline \multirow{2}{*}{ Pernyataan } & \multicolumn{5}{|c|}{ Proporsi Jawaban Responden (\%) } & \multirow{2}{*}{ Rata-rata } & \multirow{2}{*}{ Kriteria } \\
\hline & STS & TS & $\mathbf{N}$ & $\mathbf{S}$ & SS & & \\
\hline $\begin{array}{l}\text { Anda mendapatkan kepuasan } \\
\text { setelah berbelanja di Foodmart } \\
\text { Primo Lippo Mall Kuta }\end{array}$ & 0 & 1,7 & 7 & 59,1 & 32,2 & 4,22 & Baik \\
\hline $\begin{array}{l}\text { Anda mendapatkan kesenangan } \\
\text { saat berbelanja di Foodmart } \\
\text { Primo Lippo Mall Kuta }\end{array}$ & 0 & 2,6 & 18,3 & 55,7 & 23,5 & 4 & Baik \\
\hline $\begin{array}{l}\text { Anda akan melakukan pembelian } \\
\text { lagi di Foodmart Primo Lippo } \\
\text { Mall Kuta }\end{array}$ & 0 & 0,9 & 9,6 & 59,1 & 30,4 & 4,19 & Baik \\
\hline $\begin{array}{l}\text { Anda akan memberikan } \\
\text { rekomendasi kepada kerabat } \\
\text { terdekat untuk lebih memilih } \\
\text { berbelanja di Foodmart Primo } \\
\text { Lippo Mall Kuta }\end{array}$ & 0 & 1,7 & 19,1 & 43,5 & 35,7 & 4,13 & Baik \\
\hline \multicolumn{6}{|c|}{ Rata-rata } & 4,13 & Baik \\
\hline
\end{tabular}

Sumber: Data Diolah, 2017

Hasil tersebut mengindikasikan bahwa model persamaan regresi tersebut berdistribusi normal karena nilai Asymp. Sig. (2-tailed) 0,796 lebih besar dari nilai alpha 0,05 . Nilai tolerance dan VIF dari seluruh variabel tersebut memiliki nilai tolerance untuk setiap variabel lebih besar dari $10 \%$ dan nilai VIF lebih kecil dari 10 yang berarti model persamaan regresi bebas dari multikolinearitas. Nilai Signifikansi dari variabel merchandise, harga, promosi, pelayanan, lokasi dan atmosfer gerai masing-masing sebesar 0,$881 ; 0,113 ; 0,699 ; 0,767 ; 0,869$ dan 0,871 . Nilai tersebut lebih besar dari 0,05 yang berarti tidak terdapat pengaruh antara variabel bebas terhadap absolute residual. Dengan demikian, model yang dibuat tidak mengandung gejala heteroskedastisitas.

Pengujian data dalam penelitian ini menggunakan teknik analisis regresi linier berganda. Perhitungan koefisien regresi linier berganda dilakukan dengan 
analisis regresi melalui software SPSS 18.0 for Windows, diperoleh hasil yang ditunjukan pada Tabel 8 berikut. Berdasarkan hasil analisis regresi linier berganda seperti yang disajikan pada Tabel 8 , maka persamaan strukturalnya adalah sebagai berikut:

$$
\begin{aligned}
\mathrm{Y} & =\beta_{1} X_{1}+\beta_{2} X_{2}+\beta_{3} X_{3}+\beta_{4} X_{4}+\beta_{5} X_{5}+\beta_{6} X_{6}+\mathrm{e} \\
& =0,179 \mathrm{X} 1+0,377 \mathrm{X} 2+0,190 \mathrm{X} 3+0,134 \mathrm{X} 4+0,159 \mathrm{X} 5+0,205 \mathrm{X} 6
\end{aligned}
$$

Tabel 8

Hasil Analisis Regresi Linier Berganda

\begin{tabular}{lcc}
\hline \multicolumn{1}{c}{ Variabel } & Nilai Koefisien Regresi & Signifikansi \\
\hline Merchandise $\left(\mathrm{X}_{1}\right)$ & 0,179 & 0,005 \\
Harga $\left(\mathrm{X}_{2}\right)$ & 0,377 & 0 \\
Promosi $\left(\mathrm{X}_{3}\right)$ & 0,19 & 0,003 \\
Pelayanan $\left(\mathrm{X}_{4}\right)$ & 0,134 & 0,029 \\
Lokasi $\left(\mathrm{X}_{5}\right)$ & 0,159 & 0,015 \\
Atmosfer Gerai $\left(\mathrm{X}_{6}\right)$ & 0,205 & 0,001 \\
\hline R Square & & $\mathbf{0 , 6 9}$ \\
Adjusted R Square & & $\mathbf{0 , 6 7 3}$ \\
F Statistik & & $\mathbf{4 0 , 0 7 5}$ \\
Signifikansi & & $\mathbf{0}$ \\
\hline Sumber: Data Diolah 2017 & &
\end{tabular}

Sumber: Data Diolah, 2017

Tabel 8 menunjukkan nilai determinasi total (R Square) sebesar 0,690 mempunyai arti bahwa sebesar $69 \%$ variasi kepuasan pelanggan dipengaruhi oleh variasi merchandise, harga, promosi, pelayanan, lokasi, dan atmosfer gerai, sedangkan sisanya sebesar 31\% djelaskan oleh faktor lain yang tidak dimasukkan ke dalam model. Nilai Fhitung > Ftabel, 40,075 > 2,18, dengan nilai signifikansi 0,000 < 0,05. Maka H0 ditolak pada taraf nyata 0,05 ( $\mathrm{H}_{1}$ diterima). Kesimpulannya, pada kelompok yang diuji memiliki perbedaan yang nyata (signifikan). Hasil ini mempunyai arti bahwa retail mix (merchandise, harga, promosi, pelayanan, lokasi toko, atmosfer gerai) secara serempak berpengaruh signifikan terhadap kepuasan pelanggan pada Foodmart Primo Lippo Mall Kuta. 
Berdasarkan hasil analisis pengaruh Merchandise terhadap Kepuasan Pelanggan pada Tabel 4.19 diperoleh nilai Signifikasi sebesar 0,005 dengan nilai koefisien beta 0,179. Nilai Signifikansi $0,005<0,05$ menunjukkan bahwa $\mathrm{H}_{0}$ ditolak dan $\mathrm{H}_{1}$ diterima. Hasil ini mempunyai arti bahwa Merchandise berpengaruh positif dan signifikan terhadap Kepuasan Pelanggan Foodmart Primo Lippo Mall Kuta. Hasil analisis pengaruh Harga terhadap Kepuasan Pelanggan diperoleh nilai Signifikansi sebesar 0,000 dengan nilai koefisien beta 0,377. Nilai Signifikansi $0,000<0,05$ menunjukan bahwasannya $\mathrm{H}_{0}$ ditolak dan $\mathrm{H}_{1}$ diterima. Dari hasil tersebut dapat ditarik kesimpulan yaitu Harga memberikan pengaruh positif serta signifikan kepada customer satisfactory Foodmart Primo Lippo Mall Kuta. Hasil analisis pengaruh promosi terhadap kepuasan pelanggan diperoleh nilai signifikansi sebesar 0,003 dengan nilai koefisien beta 0,190 . Nilai signifikansi $0,003<0,05$ menunjukkan bahwasannya $\mathrm{H}_{0}$ ditolak dan $\mathrm{H}_{1}$ diterima. Hasil ini memberikan kesimpulan yaitu Promosi memberikan pengaruh positif serta signifikan kepada customer satisfactory Foodmart Primo Lippo Mall Kuta.

Hasil analisis pengaruh Pelayanan terhadap Kepuasan Pelanggan diperoleh nilai signifikansi sebesar 0,029 dengan nilai koefisien beta 0,134 . Nilai signifikansi $0,029<0,05$ mengindikasikan bahwa $\mathrm{H}_{0}$ ditolak dan $\mathrm{H}_{1}$ diterima. Hasil ini mempunyai arti bahwa Pelayanan berpengaruh positif dan signifikan terhadap Kepuasan Pelanggan Foodmart Primo Lippo Mall Kuta. Hasil analisis pengaruh Lokasi terhadap Kepuasan Pelanggan diperoleh nilai signifikansi sebesar 0,015 dengan nilai koefisien beta 0,159. Nilai signifikansi $0,015<0,05$ mengindikasikan bahwa $\mathrm{H}_{0}$ ditolak dan $\mathrm{H}_{1}$ diterima. Hasil ini mempunyai arti 
bahwa Lokasi berpengaruh positif dan signifikan terhadap Kepuasan Pelanggan Foodmart Primo Lippo Mall Kuta. Hasil analisis pengaruh atmosfer gerai terhadap Kepuasan Pelanggan diperoleh nilai signifikansi sebesar 0,001 dengan nilai koefisien beta 0,205 . Nilai signifikansi $0,001<0,05$ mengindikasikan bahwa $\mathrm{H}_{0}$ ditolak dan $\mathrm{H}_{1}$ diterima. Hasil ini mempunyai arti bahwa atmosfer gerai berpengaruh positif dan signifikan terhadap Kepuasan Pelanggan Foodmart Primo Lippo Mall Kuta.

Hasil analisis menunjukkan bahwa retail mix (merchandise, harga, promosi, pelayanan, lokasi toko, atmosfer gerai) secara serempak berpengaruh positif signifikan terhadap kepuasan pelanggan. Hal ini memiliki makna bahwa semakin baik penerapan retail mix pada Foodmart Primo Lippo Mall Kuta maka semakin bertambah pula tingkat kepuasan pelanggan. Begitu pula sebaliknya, semakin buruk penerapan retail mix pada Foodmart Primo Lippo Mall Kuta maka semakin rendah tingkat kepuasan pelanggan tersebut. Hasil tersebut mengindikasikan bahwa strategi yang terkandung dalam retail mix mampu dipersepsikan dengan baik dan berdampak nyata terhadap kepuasan pelanggan pada Foodmart Primo Lippo Mall Kuta. Hasil penelitian sesuai dengan penelitian sebelumnya oleh Artha (2013) dan Arokiasamy (2012) menemukan yaitu strategi bauran ritel tersebut terdiri atas barang dagangan, harga, communication, desain toko, pelayanan pelanggan dan lokasi dengan terus menerus memberikan pengaruh signifikan kepada customer satisfaction.

Hasil analisis menunjukkan bahwa masing-masing variabel retail mix yang terdiri dari merchandise, harga, promosi, pelayanan, lokasi toko, atmosfer gerai 
memiliki pengaruh positif dan signifikan terhadap Kepuasan Pelanggan Foodmart Primo Lippo Mall Kuta. Hal ini memiliki makna bahwa retail mix secara parsial berpengaruh positif terhadap Kepuasan pelanggan pada Foodmart Primo Lippo Mall Kuta. Berarti bahwa semakin menarik merchandise, semakin baik harga, semakin menarik promosi, semakin baik pelayanan, semakin mudah jangkauan lokasi toko, dan semakin nyaman atmosfer gerai Foodmart Primo Lippo Mall Kuta yang diberikan, maka akan semakin bertambah tingkat kepuasan pelanggan.

\section{SIMPULAN DAN SARAN}

Berdasarkan hasil analisis penelitian dan hasil pembahasan di atas, maka dapat ditarik simpulan yaitu: 1) Retail mix (merchandise, harga, promosi, pelayanan, lokasi toko, atmosfer gerai) secara simultan berpengaruh signifikan terhadap kepuasan pelanggan pada Foodmart Primo Lippo Mall Kuta. Hal ini memiliki makna bahwa semakin baik penerapan retail mix pada Foodmart Primo Lippo Mall Kuta maka semakin bertambah pula tingkat kepuasan pelanggan. 2) Retail mix yang terdiri dari (merchandise, harga, promosi, pelayanan, lokasi toko, atmosfer gerai) secara parsial memiliki pengaruh positif dan signifikan terhadap Kepuasan Pelanggan Foodmart Primo Lippo Mall Kuta. Hal ini memiliki makna bahwa semakin menarik merchandise, semakin baik harga, semakin menarik promosi, semakin baik pelayanan, semakin mudah jangkauan lokasi toko, dan semakin nyaman atmosfer gerai Foodmart Primo Lippo Mall Kuta yang diberikan, maka akan semakin meningkatkan kepuasan pelanggan.

Berdasarkan hasil pembahasan dan simpulan yang sudah dipaparkan, maka saran yang dapat disampaikan sebagai berikut: 1) Bila ditinjau dari aspek 
merchandise yang menunjukkan bahwa masih terdapat pelanggan yang merasa setiap jenis produk yang ditawarkan di Foodmart Primo Lippo Mall Kuta kurang lengkap, maka sebaiknya pihak manajemen menambah ragam jenis produk yang ditawarkan agar menjadi lebih lengkap. 2) Bila ditinjau dari aspek harga yang menunjukkan bahwa masih terdapat pelanggan yang tidak setuju jika dikatakan harga di Foodmart Primo Lippo Mall Kuta lebih murah dibandingkan retail lainnya, maka sebaiknya pihak manajemen Foodmart Primo Lippo Mall Kuta meninjau kembali harga setiap produk yang ditawarkan, agar dapat bersaing dari segi harga dengan retail lainnya. 3) Bila ditinjau dari aspek promosi yang menunjukkan bahwa Foodmart Primo Lippo Mall Kuta masih kurang mengadakan undian dengan berbagai hadiah yang menarik, maka sebaiknya pihak manajemen Foodmart Primo Lippo Mall Kuta mengadakan undian yang menarik setiap bulannya dengan berbagai hadiah yang dapat memuaskan pelanggan. 4) Bila ditinjau dari aspek pelayanan yang menunjukkan bahwa masih terdapat pelanggan yang tidak setuju jika dikatakan waktu buka dan tutup gerai disediakan Foodmart Primo Lippo Mall Kuta sudah sesuai dengan yang diinformasikan, maka sebaiknya pihak manajemen Foodmart Primo Lippo Mall Kuta meninjau kembali waktu buka dan tutup gerai agar sesuai dengan yang diinformasikan kepada pelanggan. 5) Bila ditinjau dari aspek lokasi yang menunjukkan bahwa masih terdapat pelanggan yang tidak setuju jika dikatakan akses menuju Foodmart Primo Lippo Mall Kuta mudah dan lancar, maka sebaiknya pihak manajemen Foodmart Primo Lippo Mall Kuta lebih mempermudah akses menuju Foodmart Primo Lippo Mall Kuta. 6) Bila ditinjau dari aspek atmosfer gerai yang 
menunjukkan bahwa masih terdapat pelanggan yang merasa kurang nyaman dengan suhu udara di Foodmart Primo Lippo Mall Kuta, maka sebaiknya pihak manajemen Foodmart Primo Lippo Mall Kuta memperbaiki kembali sistem pengaturan udara dengan AC pada gerai tersebut, agar sesuai dengan keinginan pelanggan. 7) Bila ditinjau dari aspek kepuasan pelanggan dalam peneltiian ini yang menunjukkan bahwa masih terdapat pelanggan Foodmart Primo Lippo Mall Kuta yang merasa kurang mendapatkan kesenangan saat berbelanja di Foodmart Primo Lippo Mall Kuta, maka sebaiknya pihak Foodmart Primo Lippo Mall Kuta dapat meningkatkan suasana yang nyaman bagi pelanggan saat sedang berbelanja, menyediakan fasilitas fisik dan kualitas produk yang memadai, memberikan pelayanan yang cepat dan baik sesuai kebutuhan pelanggan, selalu sigap dalam melayani pelanggan, serta selalu ramah dan sopan kepada semua pelanggan. 8) Melihat keterbatasan yang ditemukan pada penelitian ini, peneliti selanjutnya juga diharapkan untuk memperluas ruang lingkup wilayah penelitian dan lokasi penelitian sehingga hasil penelitian dapat diimplementasikan secara umum.

\section{REFERENSI}

Ali, Siti Rapidah Omar., Wan Nur Salini Wan Ibrahim., Nur Shafini Mohd Said., Khalid Amin Mat., and Hani Sakina Mohamad Yusof. 2017. Customer Satisfaction in the Retail Industry: The 4Ps of Marketing Mix. Journal of Applied Environmental and Biological Sciences. 7(4): 131-135.

Alma, Buchari. 2005. Manajemen Pemasaran dan Pemasaran Jasa, Edisi Revisi. Alfabeta, Bandung.

Anggoro, Sandra Puspasari. 2013. Analisis Pengaruh Store Atmosphere Terhadap Impulse Buying melalui Emotional Response di Matahari Department Store Tunjungan Plaza Surabaya. Jurnal Widya Mandala Surabaya, 1(3): 1-13 
Anggraeni, Debbie. 2014. Pengaruh Retail Mix Terhadap Keputusan Pembelian Pada Bali Cenik Kids Apparel di Denpasar. Skripsi. Universitas Udayana.

Arinanda, Hendrikus. 2009. Analisis Variabel Pembentuk Kepuasan Konsumen pada Ritel Minimarket Alfamart dan Indomaret di Wilayah Pesanggarahan Jakarta Selatan. Jurnal Manajemen: Fakultas Ekonomi Universitas Gunadarma, Jakarta.

Arokiasamy, Anantha Raj A. 2012, "The Effect of Marketing Mix and Customer Perception on Brand Loyalty", Journal of Business and Management, 4 (2): $1-11$

Artha, Farid. 2013. Analisis Pengaruh Retailing Mix Terhadap Kepuasan Pelanggan dan Dampaknya Terhadap Loyalitas Pelanggan pada Giant Supermarket Kota Malang. Jurnal Ilmiah Mahasiswa FEB, 1(2)

Autami, Ni Luh Md Manasaputri Sri. 2015. Pengaruh Retail Mix Terhadap Keputusan Pembelian Konsumen Pada Gerai Chat Time. Skripsi Universitas Udayana.

Borges, Adilson. 2012 .Gender orientation and Retail Atmosphere: Effects on Value Perception. Journal of Retail \& Distribution Management, 41(7): 498-511

Christoper Lovelock dan Lauren K Wright.2007. Manajemen Pemasaran Jasa, PT. Indeks, Indonesia

Coley, A., dan Burgess, B. (2003). "Gender differences in cognitive and affective impulse buying". Journal of Fashion Marketing and Management: An International Journal, 7(1): 282-295.

Cox, Roger, dan Brittain, Paul. 2008. Retail: An Introduction (5th ed.). New Jersey: Prentice Hall Internasional

Fang, Tan Yen. 2012. Pengaruh Faktor - faktor Retailing Mix Terhadap Kepuasaan Konsumen Berbelanja Di Swalayan Surya Baru Pati. Jurnal Fakultas Ekonomika dan Bisnis. Universitas Kristen Satya Wacana Salatiga.

Ferdinand. 2002. Structural equation modeling (SEM) dalam Penelitian Manajemen. Thesis. Program Magister Manajemen Universitas Diponogoro. Semarang : Universitas Diponegoro. 
Ghozali, I. 2016. Aplikasi Analisis Multivariete dengan Program IBM SPSS 23. Badan Penerbit Universitas Diponegoro. Semarang.

Grewal, Dhruv. 2009. Customer Experience management in retailing:An Oraganizing Freamework. Journal of Retailing, 85(1):1-14

Hendri, Ma'ruf. 2006. Pemasaran Ritel, Jakarta : PT. Gramedia Pustaka Utama.

Herrmann, A., Xia, L., Monroe, K. B., and Huber, F. 2007. The influence of price fairness on customer satisfaction:an empirical test in the context of automobile purchases. Journal of Product \& Brand Managemen. 16(1): $49-58$

Homburg, C., N. Koschate., dan W.D. Hoyer, 2005. Do Satisfied Customers Really Pay More? A Study of the Relationship between Customer Satisfaction and Willingness to Pay. Journal of Marketing, 69(2): 84- 96.

Katole, Hemant J. 2012. Evaluation of Retailers vs Customers Views on the Usage of Advertising as Communication Tool. International Journal of Marketing Studies. 4(6): 174-182

Kotler dan Keller, 2007. Manajemen Pemasaran, Edisi 12, Jilid 1, PT.Indeks, Jakarta.

Krisnawati, Melinda. 2016. Pengaruh Merchandising, Display Barang, dan Harga terhadap Kepuasan Pelanggan pada Toko Mina Desa Wonoasri Kecamatan Grogol. Artikel Skripsi. Fakultas Ekonomi Universitas Nusantara Persatuan Republik Indonesia. Kediri.

Kuncoro, Mudrajad. 2009. Metode Riset Untuk Bisnis \& Ekonomi. Penerbit Erlangga. Jakarta.

Levy dan Weitz, 2001. Retailing Management, 4th edition. New York: Mc.Graw Hill, Irwin

Levy, Michael dan Weitz, Barton A., 2009. Retailing Management. New York, America: McGraw-Hill/Irwin.

Lu, Y. dan Y. Seock, 2008. The influence of grey consumers service quality perception on satisfaction and store loyalty behavior. Internasional Journal of Retail \& Distribution Management. 36: 907-918

Maheza,Vincentius Gentha., dan Kusumadewi, Ni Made Wulandari. 2015. Pengaruh Retail mix Terhadap Kepuasan Pelanggan pada Unagi Bali 
Handycraft and Souvenir Gallery di Kota Denpasar. E-Jurnal Manajemen Unud, 4(7): 1881-1901

Melissa. 2010. Pengaruh Retail Service dan Store Image terhadap Kepuasan dan Loyalitas Pelanggan di Pepito Supermarket Kuta-Bali. Tesis. Program Studi Magister Manajemen Universitas Udayana, Denpasar.

Mowen, John, C., dan Michael Minor. 2002. Perilaku Konsumen. Jilid Kedua. Jakarta: Erlangga.

Nitisusastro, Mulyadi. 2012. Perilaku Konsumen Dalam Perspektif Kewirausahaan. Bandung : Alfabeta.

Nurbiyanto, Bayu., Suharyono., dan Kumadji, Srikandi. 2010. Pengaruh Bauran Retail (Retailing Mix) Terhadap Keputusan Pembelian. Jurnal Adminitrasi Bisnis, 2(2): 68-84

Riaz, W. and A. Tanveer, 2012. Marketing Mix, Not Branding. Asian Journal of Business and Management Sciences, 1(11): 43-52.

Sandra Puspasari Anggoro. 2013. Analisis pengaruh store atmosphere terhadap implusif buying melalui emotional response di matahari department store tunjungan plaza surabaya. E-Journal, Surabaya: Universitas Katolik Widya Mandala

Satnam, Ubeja., 2010. A Study of Sales Promotion Mix on Customer Satisfaction With Reference to Shopping Malls in Indore Global. Journal of Finance and Management. 6 (3): 245-252

Sopiah dan Syihabuddin. 2008. Bisnis Ritel. Yogyakarta : Andi

Sugiyono. 2014. Metode Penelitian Kuantitatif, Kualitatif, dan Kombinasi (Mixed Methods). Bandung : Alfabeta

Supiatni, Ni Nyoman. 2012. Penilaian konsumen Terhadap penerapan Bauran Pemasaran Ritel pada Toko segar Buah Denpasar. Jurnal Bisnis dan Kewirausahaan, 8(1): 20-30

Tim, Lili dan Dion Dewa Barata. 2017. Pengaruh Atmosfer Gerai, Promosi Penjualan dan Pelayanan Ritel terhadap Kepuasan Pelanggan dan Dampaknya terhadap Loyalitas Pelanggan Ritel di Lotte Mart Kelapa Gading. Jurnal Bisnis dan Komunikasi. Kalbisocio, 4(1) 
Tiwari, Deepak., Supriti Dubey, P.K.Chopra., dan Mansi, Jain. 2015. Impact of Merchandising on Customer satisfaction and thereby on Retailers' sale. International Journal of Engineering and Applied Sciences. 2(2).

Tjiptono, Fandi. 1997. Strategi Pemasaran. Edisi kedua. Andi: Yogyakarta.

Turley, L. W., \& Milliman, R. E. (2000). Atmospheric affects on shopping behaviour a review of the experimental. Journal of Business Research, 49 (1): 193-211.

Utami, Christina Widhya. 2010. Manajemen Ritel. Jakarta: Salemba Empat

Varki, S. dan Colgate, M. 2001. The role of price perceptions in an integrated model of behavioral intentions, Journal of Service Research, 3(3): 232240.

White, Darin W. dan Absher, Keith. 2007. Positioning of Retail Stores in Central and Eastern European Accession States. European Journal of Marketing. 41(3/4): 131-145

Widoretno. 2014. Analisis Pengaruh Bauran Pemasaran Ritel Terhadap Kepuasan Dan Loyalitas Pelanggan Berbelanja Di Giant Hypermarket Kota Pekanbaru. Jurnal Tepak Manajemen Bisnis. 6(2).

Yistiani, Ni Nyoman Manik dkk. 2012. Pengaruh Atmosfer Gerai dan Pelayanan Ritel terhadap Nilai Hedonik dan Pembelian Impulsif Pelanggan Matahari Departement Store Duta Plaza di Denpasar, Jurnal Manajemen, Strategi Bisnis, dan Kewirausahaan, 6(2): 139-147.

Yulianti, Ni Made Dhian Rani. 2017. Pengaruh Merchandising, Basic Principles, dan Retail Services terhadap Perilaku Hedonik dan Kepuasan Konsumen pada Discovery Shopping Mall. Media Bina Ilmiah. Universitas Pendidikan Nasional. 11 (1). 